\title{
INFORMATIVE ENVIRONMENT QUALIFYING INDEX
}

\author{
ANETT UTASI *1 , VIKTOR SEBESTYÉN ${ }^{1}$, AND ÁKOS RÉdEY ${ }^{1}$ \\ 'Sustainability Solutions Research Lab, University of Pannonia, Egyetem u. 10, Veszprém, 8200, \\ HUNGARY
}

\begin{abstract}
Improvement in the quality of the environment and, as a result, in the quality of life, including environmental impact assessments and environmental management, play an important role in the practical implementation of environmental regulations.

The goal of this paper is to develop a new type of quantitative environmental impact assessment method to describe changes in environmental elements as well as the environment in an objective and reliable manner for various projects, investments, plans and proposals. An easily adaptable method was sought which provides a clear and well-interpretable result on the condition of and foreseeable changes in the environment.

The algorithm operates using the limit values of environmental elements set forth by national regulations. The evaluation is independent of the number of environmental parameters chosen as it was included in the informativity rates of the method. The process results in an aggregated index for qualifying the total environment but, nonetheless, the affected environmental elements and measured environmental parameters can be analysed independently. The Informative Environment Qualifying Index evaluates the environmental parameters in proportion to the strictness of the limit values. The final assessment of the total environment is performed by using varying intervals, therefore, the different cases can be compared to each other. Experts interpret the results as well as explain the changes in the state of the environment and, therefore, identify the cause-effect relationships.
\end{abstract}

Keywords: Environmental Impact Assessment, Quantitative methods, Informative Environment Qualifying Index, Environmental pollution

\section{Introduction}

The state of the environment has been changing drastically in an unfavourable direction due to economic development, rapid population growth, as well as increases in the rates of production and consumption resulting in extremely severe levels of environmental pollution amongst several other consequences. The European Union itself is committed to introduce actions and measures in order to take preventive steps to protect the environment. Regarding immediate actions to be implemented, environmental protection is an essential objective.

The Environmental Impact Assessment (EIA) and sustainability planning are intertwined. Both approaches aim to optimize future activities in an environmentally sound way and support decision-makers with appropriate, scientifically based evidence. Analyses must provide quantified information as well as easily understandable and comparable results, therefore, the aggregation of quantitative methods is widespread. The aim of this work is to develop an informative environment qualifying index. In addition to indexing based on immission limits, it is important to evaluate the sustainability of cities, for

\footnotetext{
*Correspondence: utasi.anett@uni-pannon.hu
}

which the SDEWES Index is an excellent approach [1]. This method has been implemented in Southeast European cities [2] and adapted for Hungarian cities [3].

Toro et al. developed a qualitative methodology for Environmental Impact Assessment (EIA) processes, which uses a double matrix to identify the impacts and assign quantitative values to the categories of quality [4].

Pavlickova and Vyskupova elaborated on a cumulative method for the evaluation of landscape vulnerability by taking this as well as ecological stability and the ratio of different measures of stability into account [5]. Herva and Roca reviewed the combined approaches and multicriteria analysis for the purposes of evaluating corporate environmental performance. It was suggested to use the Multi-Criteria Decision-Making (MCDM) techniques in the industrial sector, decision-making in energy projects, waste management and wastewater treatment [6].

A possible method is the Environmental Impact Assessment, which comprises 25 different EIA methods as well as uses a quantitative framework and standard classification method as an optimal technique for the actual evaluation [7].

An integrated weight of evidence approach for environmental risk assessment proposed by Caeiro et al. 
where anthropogenic pollution, the impacts on human health, the exposition of polluted wells and agricultural soils as well as pollutants in sediments are combined with 14 categories of absolute conditions [8]. Phillips used an enhanced Rapid Impact Assessment Matrix (RIAM) method to evaluate quantitatively the potential impacts of an onshore wind farm during its construction and operation [9], as well as for the sustainability evaluation of municipal solid waste management [10]. The RIAM approach was successfully used by Brindusa et al. to evaluate the environmental impacts resulting from heavy metal pollution on the southern coast of the Romanian Black Sea [11]. Sun and Wang developed a comprehensive EIA system for shale-gas exploration, which includes the evaluation systems of influence with regard to the natural and macro environments. The algorithm includes social, policy and economic impacts, therefore, it can be adapted to other fields of environmental analysis [12]. Robu et al. analysed the impacts and risks of heavy metal pollutants in bodies of surface water. The basis of such evaluations was the measured concentrations of the environmental parameters, therefore, the method is more objective [13]. The reliability of the different quantitative and qualitative methods may be increased by integrating the technical background of Environmental Risk Assessment [14]. An Environmental Evaluation System (EES) that incorporates relationships between environmental parameters and environmental quality was developed by Battelle Columbus Laboratories [15] and implemented for water resources planning by Ferreira et al. [16].

A review of aquatic environmental assessment methods was published by Foden et al. in which a new classification system is suggested that differentiates between static and dynamic links [17]. Yu et al. developed a universal calibrated model for the evaluation of bodies of surface- and groundwater. The main advantage of this algorithm is that it works with any combination of water quality indicators. It was developed in accordance with Chinese legislation, therefore, must be adapted for international applications [18].

On the basis of the literature review on EIA, it can be concluded that the aforementioned methods have several benefits, however, their limits should be taken into consideration. The main advantage of such methods is their suitability to compare different project alternatives. However, in light of its practical applications, two main issues need to be addressed. Namely, the assessment is based on the limit values of environmental parameters, measured/calculated values as well as the ranking/weighting/scaling of the environmental parameters and elements. In addition to these, it can also be concluded that the methods in the literature are less sensitive to extreme values, namely to discharges above the limit values.

In addition to environmental impacts, risk assessment is important for decision-makers. Wu et al. proposed a quantitative environmental risk assessment for the iron and steel industrial symbiosis network, which provides an aggregate index value and is able to identify the most important driving forces [19]. Risks were identified in a chemical plant in Zhejiang province in China, where an index-based approach with the Analytic Hierarchy Process (AHP) and fuzzy operators was used for the evaluation [20].

The objective of this paper is to develop a new, easily adaptable, objective and reliable quantitative EIA method which provides an unambiguous outcome in the case of projects, investments, plants and proposals in comparison with the methods given in the literature. Environmental impacts should be identified during the early design phases [21] in order to avoid unlawful and polluting activities. A widely usable, target-oriented, objective and comprehensive new type of quantitative EIA technique was sought and its applicability verified.

The environmental impacts were linked to human activities in order to explore the cause-and-effect relationships, therefore, systems thinking is crucial in the case of an EIA. Rocha et al. developed a multiple indicatorbased approach for environmental quality assessment in urban areas [22]. The proposed IIEQ method is suitable for tracking environmental changes which can be linked to different human activities.

\section{Results: Methodology}

The Informative Environment Qualifying Index ( $\left.I_{\mathrm{IEQ}}\right)$ method was developed in accordance with legal and other relevant stipulations. The $I_{\mathrm{IEQ}}$ characterizing the total environment can be determined as depicted in Fig. 1.

The environmental assessment of alternatives to the project begins with screening the projects according to the applicable laws and regulations. The preparation of a reference databased Bepends on the scope of the analysis. Firstly, the relevant environmental elements must be selected and their limit values determined. Following the preparation of the database, the algorithm is expanded by defining the environmental parameters studied for the selected environmental elements and the weighting of these parameters determined. The workflow of the method has been developed in such a way that it can be used to study an individual environmental element or complex cases, e.g. where several environmental elements are considered simultaneously. By analysing the environmental parameters (the second block in Fig. 1 which qualify the given environmental element, it is possible to plan the optimal mitigation strategy for that element. Therefore, the driving forces/drivers in the quality of the element are identified. The analysis with regard to the level of the environmental element provides a comprehensive picture of the state of the studied elements and important information in the evaluation of the environmental impacts of the projects. The environmental analysis (the last block in Fig. 1) ensures a basis for the comparison of the different cases investigated. The $I_{\text {IEQ }}$ value helps decision-makers to determine the optimal measure or project alternative. 


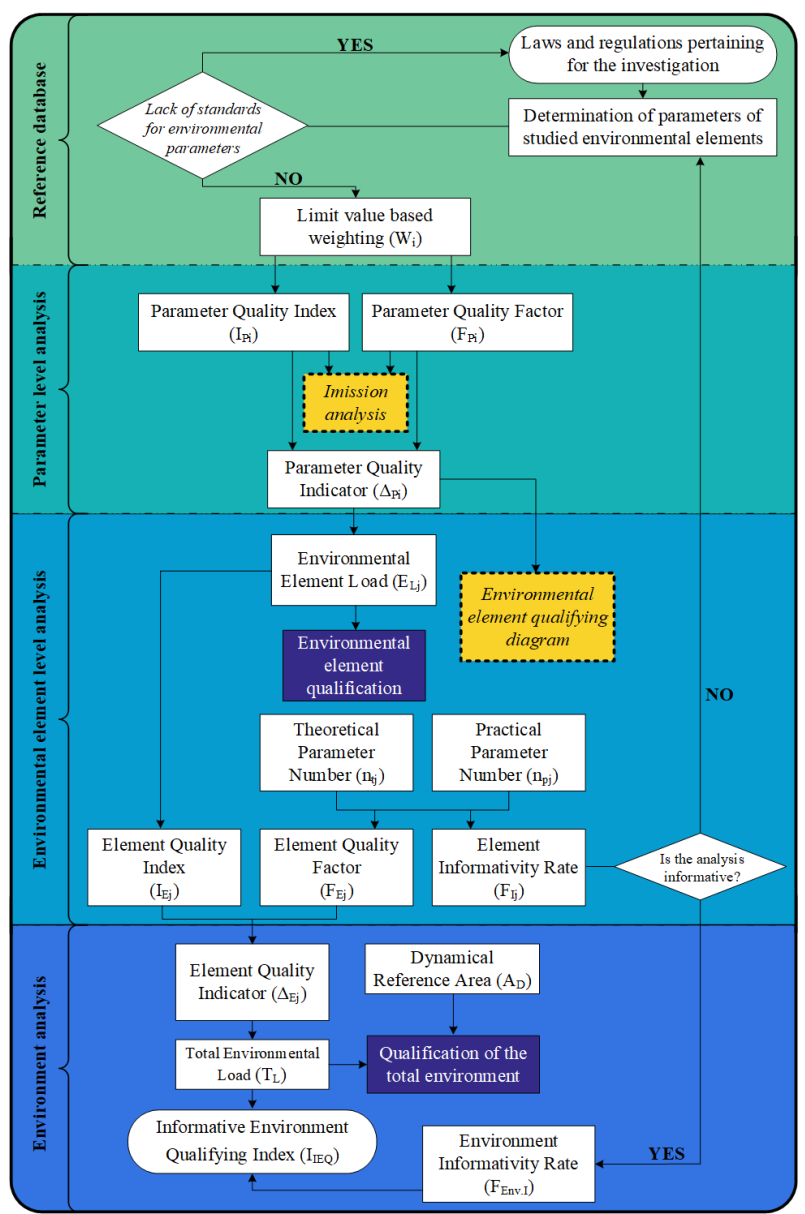

Figure 1: Methodology of the Informative Environment Qualifying Index

The method is suitable for multilevel analysis. The levels are represented by different colours in Fig. 1. The final outcome of the method is the determination of the $I_{\mathrm{IEQ}}$. These steps are discussed in the following section.

\subsection{Reference database}

\section{Laws and regulations pertaining to the investigation}

The basis for the method is the set-up of the environmental reference database according to Hungarian stipulations. When used in other countries, the reference database should be adjusted to pertain to the legal regulations of the country in question. The environmental elements are studied in the present paper in light of the Hungarian law on the environment. The following environmental elements were taken into consideration:

1. Surface water: water flows (W)

2. Surface water: lakes (L)

3. Groundwater $(\mathrm{G})$

4. Soil (S)

5. Air (A)

Some EIA techniques, which were developed for the analyses of specific environmental elements, e.g. Németh et al. provided a quantitative tool for bodies of surface water [23] to show changes in water quality of Lake Balaton, the largest natural shallow lake in Central Europe $[24,25]$. In the case of air pollution, the Air Quality Index (AQI) is a useful tool to improve public understanding and participation [26]. Calculations of AQI can be supported by the two-phase decomposition technique and machine learning [27]. Indoor Environmental Quality (IEQ) can also be taken into consideration as this was analysed in a university building [28]. The EIA techniques can be sector-specific as well, e.g. Sanz et al. developed a new well-being index to describe the environmental quality of renewable energy sources and nuclear power [29].

One of the most important goals during the development of the $\mathrm{I}_{\mathrm{IEQ}}$ was to provide a tool that facilitates the public understanding of environmental impacts in a simple, clear way, which includes more graphical representations of the impacts and is capable of describing changes in the state of the environment across an aggregated index value.

\section{Determination of the environmental parameters for the environmental elements studied}

Lists of environmental parameters are collected for every environmental element which is to be evaluated according to the pertaining stipulations. The database includes the names of the environmental parameters as well as their limit values and validity. The list for surface water is based on GD 2010 [31], the Water Framework Directive. The lists for soil as well as groundwater are based on GD 2006 [32], and the one for the environmental parameters of air can be defined on the basis of GD 2011 [33].

Environmental parameters for which no limit values are specified can be studied as well, since the numerical target for the environmental parameters should be determined by specialists and such values are to be included in the list of environmental parameters.

\section{Weight of environmental parameters}

Generally speaking, the objectivity of the EIA is compromised or questionable when a specialist defines the weighted preferences for the environmental parameters. In order to solve this problem, the authors have developed a weighting procedure based solely on environmental regulations and specifications. The hypothesis assumes that legislators took the risks and impacts of the environmental parameters into account whilst defining the limit values. The $\mathrm{I}_{\mathrm{IEQ}}$ weighting procedure defines different categories of importance with regard to the environmental elements on the basis of the order of magnitude of the limit values. To determine the confined values of the intervals, the lowest (most severe) and highest (mildest) limit values should be sought in the specifications and classified in the appropriate categories of magnitude. The other limit values should be ranked between those two 


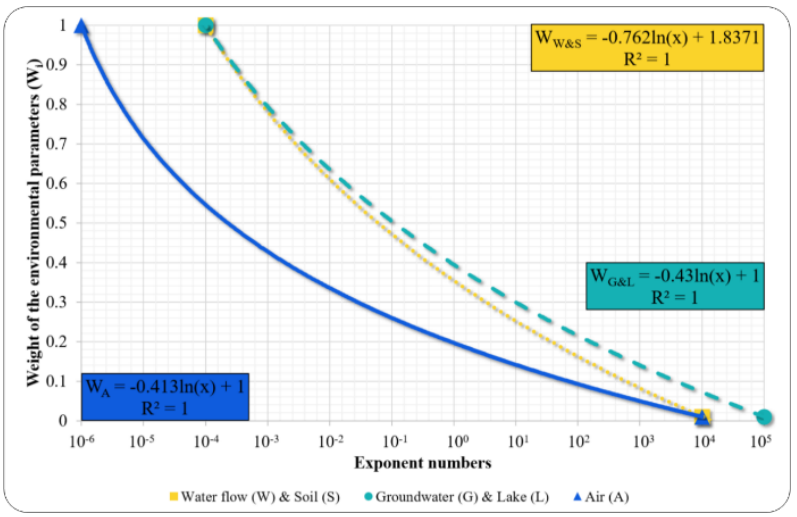

Figure 2: Weights of the various environmental elements

predefined confined values. The environmental parameters are classified by fitting a natural logarithmic curve as can be seen in Fig. 2, where the $x$ and $y$ axes indicate the magnitude and weight of the environmental parameters, respectively. Weights of 1 and 0.01 represent the most severe and mildest situations, respectively. The equations of the aligned curves are given in Fig. 2 by taking into consideration environmental elements (according to Hungarian regulations, the same magnitudes are assigned to certain environmental elements).

Fig. 2 presents the relationship between the air, bodies of surface water, soil and groundwater. Using the equations given in Fig. 2, weights, presented in Table 1, can be generated for the given environmental parameters. In the case of surface water, the limit value of $\mathrm{PO}_{4}-\mathrm{P}$ is $200 \mu \mathrm{g} / \mathrm{l}$, which belongs to the order of magnitude of $10^{2}$, therefore, its value is 0.122 . In the case of mercury, the limit value is $0.05 \mu \mathrm{g} / \mathrm{l}$, which can be assigned to the order of magnitude of $10^{-2}$, therefore, its value is 0.505 .

Table 1: Weights according to orders of magnitude

\begin{tabular}{lcccc}
\hline $\begin{array}{l}\text { Orders of magni- } \\
\text { tude of the envi- } \\
\text { ronmental parame- } \\
\text { ters studied }\end{array}$ & $\begin{array}{l}\text { Expo- } \\
\text { nent } \\
\text { of } 10\end{array}$ & $W_{\mathrm{A}}$ & $W_{\mathrm{W} \& \mathrm{~S}}$ & $W_{\mathrm{G} \& \mathrm{~L}}$ \\
\hline 0.000001 & -6 & 1 & $*_{\text {o.r. }}$ & $*_{\text {oo.r. }}$ \\
0.00001 & -5 & 0.714 & $*_{\text {o.r. }}$ & $*_{\text {o.r. }}$ \\
0.0001 & -4 & 0.546 & 1 & 1 \\
0.001 & -3 & 0.427 & 0.687 & 0.714 \\
0.01 & -2 & 0.335 & 0.505 & 0.546 \\
0.1 & -1 & 0.26 & 0.375 & 0.427 \\
1 & 0 & 0.196 & 0.274 & 0.335 \\
10 & 1 & 0.141 & 0.192 & 0.26 \\
100 & 2 & 0.093 & 0.122 & 0.196 \\
1,000 & 3 & 0.049 & 0.062 & 0.141 \\
10,000 & 4 & 0.010 & 0.010 & 0.093 \\
100,000 & 5 & $*_{0 . r .}$ & $*_{0 . r}$ & 0.01 \\
\hline
\end{tabular}

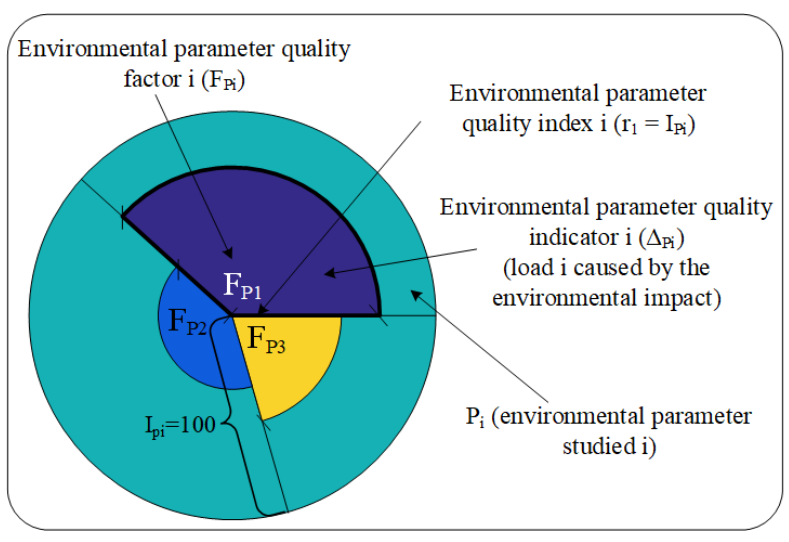

Figure 3: The qualifying diagram of an environmental element on the basis of the quality factor $\left(\mathrm{F}_{\mathrm{Pi}}\right)$, quality index $\left(\mathrm{I}_{\mathrm{Pi}}\right)$ and quality indicator $\left(\Delta_{\mathrm{Pi}_{\mathrm{i}}}\right)$ of the environmental parameter

\subsection{Analysis of Parameters}

In order to better understand the status of environmental elements, a visualization technique has been developed where the pollution/environmental load of an environmental element is represented by circles of defined radii and areas (Fig. 3). As a result, the parameters describing the environmental elements can be represented by segments of a circle (hereinafter referred to as "segment"). The following basic considerations were taken into consideration: the radii of the different segments are the ratios of the measured parameters to limit values expressed as percentages, referred to as the so-called environmental parameter quality index.

\section{Environmental parameter quality index $\left(I_{\mathbf{P} i}\right)$}

The environmental parameter quality index $\left(I_{\mathrm{P} i}\right)$ specifies the relationship between the immission concentration and limit values defined by the environmental specifications. $I_{\mathrm{P} i}$ is determined by

$$
I_{\mathrm{P} i}=\frac{M_{\mathrm{V} i}}{L_{\mathrm{V} i}} 100
$$

where $I_{\mathrm{P} i}$ is the environmental parameter quality index for parameter $i, M_{\mathrm{V} i}$ is the measured value of environmental parameter $i$, and $L_{\mathrm{V} i}$ is the limit value of environmental parameter $i$.

If the value of $I_{\mathrm{P} i}$ changes between 0 and $100 \%$, the environmental parameter meets the legal specifications. However, if it exceeds $100 \%$, the limit value is exceeded and mitigation measures must be considered.

\section{Environmental parameter quality factor $\left(F_{\mathrm{P} i}\right)$}

The environmental parameter quality factor $(\mathrm{P} i)$ is determined on the basis of the weight. The central angles $\left(F_{\mathrm{P} 1}\right.$, $\left.F_{\mathrm{P} 2}, F_{\mathrm{P} 3}\right)$ of the circle as depicted in Fig. 3 are calculated by

$$
F_{\mathrm{P} i}=W_{\mathrm{i}} \frac{360}{\sum_{l=1}^{n_{\mathrm{P} j}} W_{l}}
$$




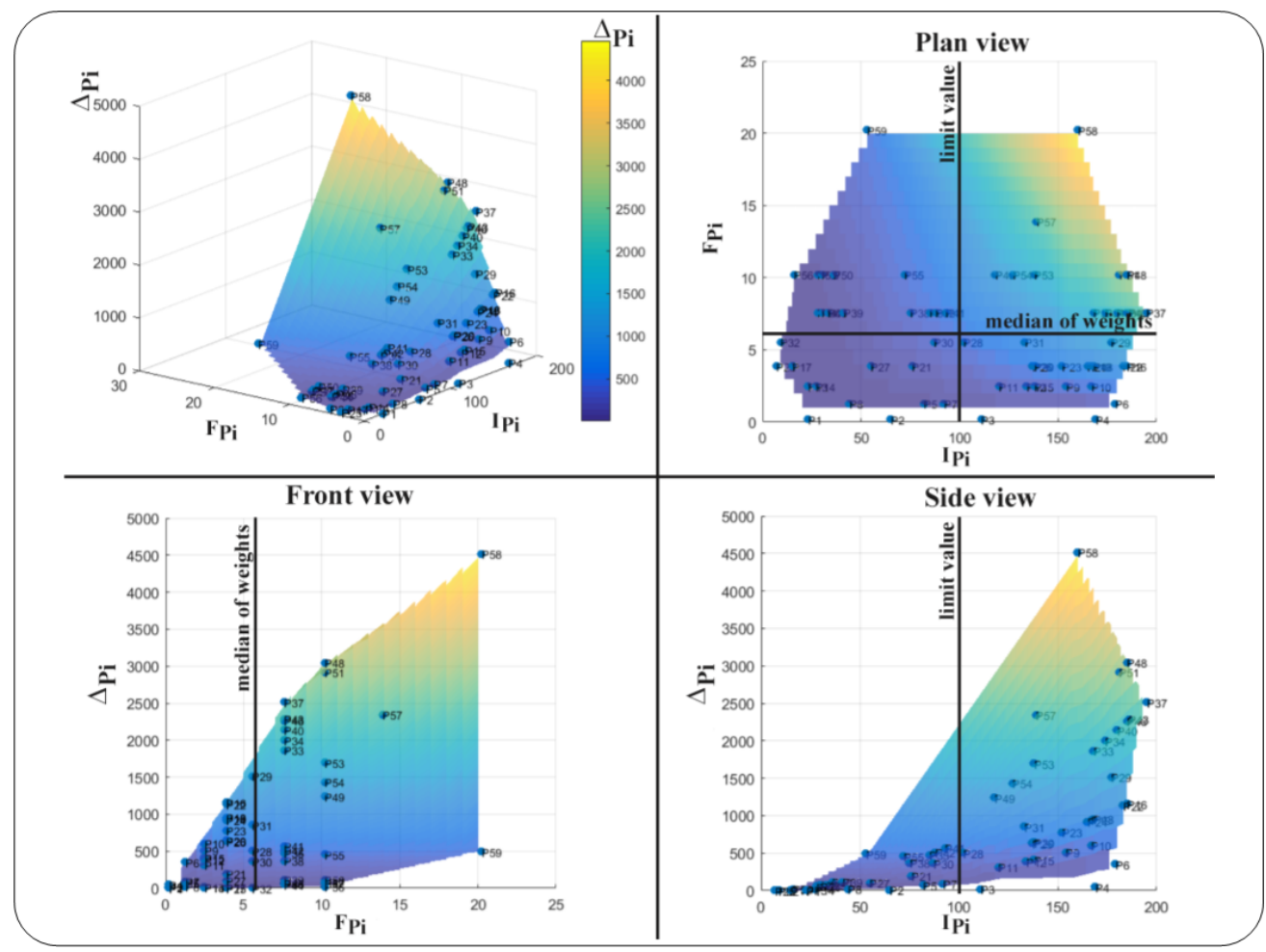

Figure 4: Immission analysis as a function of the environmental parameter quality index and factor

where $F_{\mathrm{P} i}$ is the environmental parameter quality factor for environmental parameter $i, W_{l}$ is the weight of the examined environmental parameter, and $n_{\mathrm{P} j}$ is the number of environmental parameters in the case of environmental element $i$.

\section{Environmental parameter quality indicator $\left(\Delta_{\mathrm{P} i}\right)$}

The environmental parameter quality indicator $\left(\Delta_{\mathrm{P} i}\right)$ is given by

$$
\Delta_{\mathrm{P} i}=\left(I_{\mathrm{P} i}\right)^{2} \pi \frac{F_{\mathrm{P} i}}{360}
$$

where $\Delta_{\mathrm{P} i}$ is the environmental parameter quality indicator for environmental parameter $i, I_{\mathrm{P} i}$ is the environmental parameter quality index for environmental parameter $i$ (according to Eq. 1), and $F_{\mathrm{P} i}$ is the environmental parameter quality factor for environmental parameter $i$ (according to Eq. 2). The environmental parameter quality index for environmental parameter $i$ is of square/quadratic form to emphasize the importance of the measured concentration of the parameter.

According to this interpretation, the different parameters with different units can be compared to each other so the environmental parameters can be easily qualified whether they exceed the limit values or fall within them. The central angles of the segments $\left(F_{\mathrm{P} 1}, F_{\mathrm{P} 2}, F_{\mathrm{P} 3}\right)$ represent the importance of the environmental parameter in question which is expressed as the environmental parameter quality factor as defined by Eq. 2 .

Regarding Fig. 3, the expression of the environmental parameter quality indicator is introduced based on the area of the segment (Eq. 3), which represents the extent to which the environmental parameter has an impact on the environmental element.

\section{Immission analysis}

The environmental parameters defined above can be illustrated in a three-dimensional system, therefore, the key parameters of the studied impact area identified. Fig. 4 illustrates the environmental parameter quality indicators $\left(\Delta_{\mathrm{P} i}\right)$ as a function of the environmental parameter quality factor $\left(F_{\mathrm{P} i}\right)$ and the environmental parameter quality index $\left(I_{\mathrm{P} i}\right)$. Fig. 4 shows the environmental parameters, their risks and the environmental damage caused should their values be extreme. According to the Informative Environment Qualifying Index method, the risk is a function of the specified limit value or target.

The following conclusions can be drawn on the basis of Fig. 4 . The area $\left(X_{\min } ; Y_{\min } ; Z_{\min }\right)$ represents the group of environmental parameters for which the limit values are mildest and present in low concentrations, therefore, their negative impact on the environment is minimal.

The point $\left(X_{\max } ; Y_{\max } ; Z_{\max }\right)$ represents the group of environmental parameters for which the limit values are most severe and present in high concentrations, therefore, their negative impact on the environment is maximal.

According to the protocol defined here, the key factors can be identified on the basis of a system-oriented method and the outcome of the analysis used for plan- 


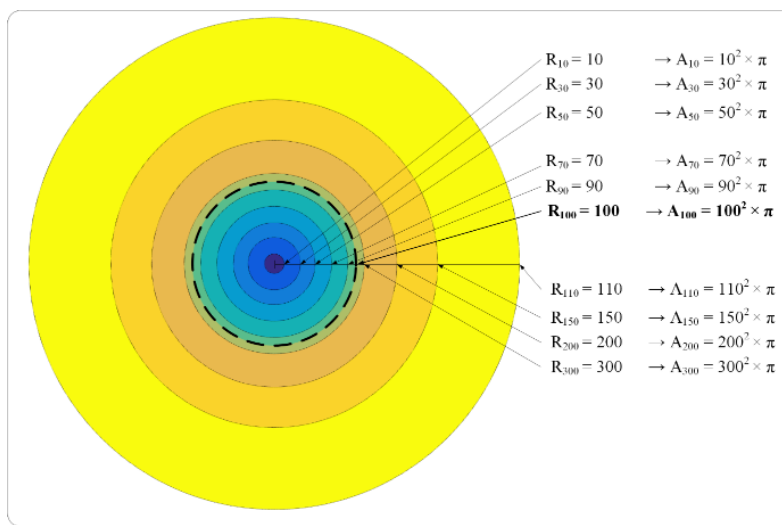

Figure 5: The relationship between the load of the environmental element and the reference areas

ning the environmental mitigation measures.

\subsection{Analysis of the Environmental element level}

The analysis of the environmental element level provides information to specialists about the cumulative impact of the environmental parameters on the environmental element in question.

\section{Load of environmental elements $\left(E_{\mathrm{L} j}\right)$}

The cumulative environmental impacts of the environmental elements can be determined by totalling the environmental parameter quality indicators $\left(\Delta_{\mathrm{P} i}\right)$, which are equal to the sum of the areas of the segments. The environmental element can be interpreted as a circle and the total levels of pollution stemming from the environmental parameters are represented by circles with different radii (Fig. 5).

In Fig. 4, the circle with $R=100$ represents the case when the load of the environmental element is equal to the total limit load of the environmental parameters.

\section{Qualification of environmental elements}

For the numerical evaluation of an environmental element, the relationships required are defined in Table 2. On the basis of the outcome of case studies and professional experience, 10 categories were defined for the environmental evaluation: 10-30-50-70-90-100-110-150200-300.

In Fig. 5, blue-coloured zones mark the acceptable categories (categories in Table 2: 10, 30 and 50), the green-coloured zones represent maximum environmental quality with regard to immission limit values (categories 70, 80 and 100), and the orange- as well as yellowcoloured zones represent situations when the level of pollution exceeds the limit value (categories 110, 150, 200 and 300).

Given these defined categories, the relative radius can be calculated from which, after working out the area of the circle $\left(A_{\mathrm{S}}=R^{2} \pi\right)$, the corresponding area can be determined $\left(A_{\mathrm{S}}\right)$. This corresponding area can be interrelated to the load of the environmental parameters studied, that is to the total area of the segments $\left(E_{\mathrm{L} j}\right)$ representing the environmental parameters.

From the load of the environmental parameters, the total area can be calculated by a numerical evaluation. The qualification/level of pollution of the environmental element can be determined from Table 2. The interval when the Load of the Environmental Element $\left(E_{\mathrm{L} j}\right)$ is less than the reference area $\left(A_{\mathrm{S}}\right)$ needs to be determined.

Table 2 can be used generally to evaluate all environmental elements and is independent from the number of environmental parameters with regard to the environmental elements since the environmental parameter quality factors $\left(F_{\text {lip }}\right)$ are normalized for $360^{\circ}$. The values of the environmental parameter quality factors depend on the number of environmental parameters and their weights.

\section{Theoretical Number of Environmental Parameters $\left(n_{\mathrm{t} j}\right)$}

The theoretical numbers of environmental parameters define the number of environmental parameters to be measured as well as monitored according to the stipulations and are based on the reference database. They are summarized in Table 3:

\section{Practical Number of Environmental Parameters $\left(n_{\mathrm{p} j}\right)$}

During the environmental impact assessment, specialists define the environmental elements to be studied and the scope of the environmental parameters. The set of environmental parameters can be different in the case of a natural environment, post-disaster situation or artificial environment. The method puts a special emphasis on the determination of the uncertainties.

\section{Element Quality Index $\left(I_{\mathrm{E} j}\right)$}

The element quality index determines how the immission concentrations are related to the pollutants to be theoretically released into the environment:

$$
I_{\mathrm{E} j}=\sqrt{\frac{E_{\mathrm{L} j}}{\pi}}
$$

where $I_{\mathrm{E} j}$ is the element quality index for environmental element $j$ and $E_{\mathrm{L} j}$ is the environmental load of environmental element $j$.

\section{Element Quality Factor $\left(F_{\mathrm{E} j}\right)$}

The element quality factor $\left(F_{\mathrm{E} j}\right)$ specifies the weight of the environmental element during the evaluation process. The goal of this factor is to take the number of environmental parameters into consideration (Eq. 7):

$$
F_{\mathrm{E} j}=\frac{n_{\mathrm{p} j} 360}{\sum_{k=1}^{m} n_{\mathrm{t} k}}
$$


Table 2: The qualification system for evaluating the different environmental elements

\begin{tabular}{lll}
\hline Reference radius $(R)$ & Reference area $\left(A_{\mathrm{S}}\right)$ & Evaluation \\
\hline 300 & 282743 & The environmental element is seriously damaged which the ecosystem cannot tolerate. \\
200 & 125664 & Natural regeneration is impossible because the environmental element is seriously damaged. \\
150 & 70686 & Natural regeneration is inhibited because the environmental element is damaged. \\
110 & 38013 & The concentrations of the environmental parameters defining the environmental element exceed the limit value. \\
100 & 31416 & The concentrations of the environmental parameters defining the environmental element are equal to the limit values. \\
90 & 25447 & The concentrations of the environmental parameters defining the environmental element are close to the limit value. \\
70 & 15394 & The environmental element with environmental parameters below the limit value or influenced by anthropogenic impacts. \\
50 & 7854 & The environmental element with minimal disturbances. \\
30 & 2827 & The natural environmental element with indirect or direct anthropogenic impacts. \\
10 & 314 & The natural environmental element free of anthropogenic impacts. \\
\hline
\end{tabular}

where $F_{\mathrm{E} j}$ is the element quality factor for environmental element $j, n_{\mathrm{p} j}$ is the practical number of environmental parameters in the case of environmental element $j, n_{\mathrm{t} k}$ is the theoretical number of environmental parameters in the case of environmental element $j$ (Table 3), and $m$ is the number of environmental elements.

\section{Environmental Element Informativity Rate $\left(F_{\mathrm{I} j}\right)$}

The environmental element informativity rate $\left(F_{\mathrm{I} j}\right)$ represents the ratio of the number of theoretical environmental parameters $\left(n_{\mathrm{t} k}\right)$ for which legal requirements are in effect to the number of investigated environmental parameters. The ideal value of the environmental element informativity rate is equal to when all parameters set forth by the legal stipulations are involved in the investigation:

$$
F_{\mathrm{I} j}=\frac{n_{\mathrm{p} j}}{n_{\mathrm{t} k}}
$$

where $F_{\mathrm{I} j}$ is the environmental element informativity rate for environmental element $j, n_{\mathrm{p} j}$ is the practical number of environmental parameters in the case of environmental element $j$, and $n_{\mathrm{t} k}$ is the theoretical number of environmental parameters in the case of environmental element $k$ (Table 3).

\subsection{Environmental analysis}

The next step to be undertaken, following the investigation of the environmental parameters and elements, is the comprehensive analysis of the whole environment. The whole environmental system should be evaluated by taking the human, health, social, economic and cultural as-

Table 3: The theoretical numbers of environmental parameters $\left(n_{\mathrm{t} k}\right)$ for different environmental elements

\begin{tabular}{ll}
\hline Environmental element & $\begin{array}{l}\text { Theoretical number of } \\
\text { environmental parame- } \\
\text { ters (pcs) }\end{array}$ \\
\hline Surface water: water flow & 59 \\
Surface water: lake & 59 \\
Groundwater & 58 \\
Soil & 52 \\
Air & 33 \\
\hline
\end{tabular}

pects into consideration in an integrated way. It is insufficient to solely focus on the natural or artificial environment. The usability of a given project area depends on several factors, not only on the excellence of one environmental element. Therefore, a holistic approach is adopted during the evaluation.

\section{Element Quality Indicator $\left(\Delta_{\mathrm{E} j}\right)$}

The element quality indicator $\left(\Delta_{\mathrm{E} j}\right)$ enables the environmental element to be taken into consideration in light of the weights of the environmental parameters that describe the environmental element. Those environmental elements which are monitored less contribute to a lesser extent with regard to the characterization of the environment. During the analysis, the cumulative load of the environmental elements is taken into account:

$$
\Delta_{\mathrm{E} j}=I_{\mathrm{E} j}^{2} \pi \frac{F_{\mathrm{E} j}}{360}
$$

where $\Delta_{\mathrm{E} j}$ is the element quality indicator for environmental element $j, I_{\mathrm{E} j}$ is the element quality index for environmental element $j$ (according to Eq. 4), and $F_{\mathrm{E} j}$ is the element quality factor for environmental element $j$ (according to Eq. 5).

\section{Total Environmental Load $\left(T_{\mathrm{L}}\right)$}

The total environmental load $\left(T_{\mathrm{L}}\right)$ represents the proportional pollution of the whole environment, which can be generated by the summation of the element quality indicators $\left(\Delta_{\mathrm{EQj}}\right)$. The environmental load is regarded as the most important issue during the calculation of the informative environment qualifying index $\left(I_{\mathrm{IEQ}}\right)$ as defined by

$$
T_{\mathrm{L}}=\sum_{j=1}^{m} \Delta_{\mathrm{E} j}
$$

where $T_{\mathrm{L}}$ is the Total Environmental Load, $\Delta_{\mathrm{E} j}$ is the Element Quality Indicator for environmental element $j$ (according to Eq. 7), and $m$ is the number of environmental elements. 
Table 4: Evaluation table of the whole environment

\begin{tabular}{lll}
\hline Reference radius $(R)$ & Dynamical reference area $\left(A_{\mathrm{D}}\right)$ & Evaluation \\
\hline 300 & $300^{2} \pi F_{\text {Env.I }}$ & Degraded area which the ecosystems cannot accommodate. \\
200 & $200^{2} \pi F_{\text {Env.I }}$ & The natural regeneration of the environment is impossible because the area is severely damaged. \\
150 & $150^{2} \pi F_{\text {Env.I }}$ & Natural regeneration is inhibited because of the damaged area. \\
110 & $110^{2} \pi F_{\text {Env.I }}$ & The concentration of the environmental parameters exceeds the limit value. \\
100 & $100^{2} \pi F_{\text {Env.I }}$ & The concentration of the environmental parameters is equal to the limit value. \\
90 & $90^{2} \pi F_{\text {Env.I }}$ & The concentration of the environmental parameters is similar to the limit value. \\
70 & $70^{2} \pi F_{\text {Env.I }}$ & The environment is influenced by levels of pollution under the limit value and directly influenced by anthropogenic impacts. \\
50 & $50^{2} \pi F_{\text {Env.I }}$ & The environment closely resembles the natural conditions or with minimal disturbances. \\
30 & $30^{2} \pi \mathrm{F}_{\text {Env.I }}$ & The natural environment with direct or indirect anthropogenic impacts. \\
10 & $10^{2} \pi \mathrm{F}_{\text {Env.I }}$ & The natural environment free of anthropogenic impacts. \\
\hline
\end{tabular}

\section{Qualification of the total environment}

Table 4 is used to evaluate the total environment, which is based on dynamical reference areas as calculated from

$$
A_{\mathrm{D}}=R^{2} \pi F_{\text {Env.I }}
$$

where $A_{\mathrm{D}}$ is the dynamical reference area (the level of the whole environment), $R$ is the reference radius (Table 4 ), and $F_{\text {Env.I }}$ is the environment informativity rate (Eq. 10).

The basis of the dynamical reference area is the reference radius (Fig. 5 and Table 2) by which 10 different categories of quality were defined. The dynamical reference area depends on the ratio of the studied environmental parameters to the theoretical number of environmental parameters (informativity defined in the method).

The numerical assessment of the whole environment results in the element quality indices from the environmental load stemming from the total environmental parameters for the environmental elements. The evaluation of Table 4 concerns the results in terms of quality/pollution during the interval, in which case the value of the total environmental load $\left(T_{\mathrm{L}}\right)$ is less than the dynamical reference area $\left(A_{\mathrm{D}}\right)$.

\section{Environment Informativity Rate $\left(F_{\text {Env.I }}\right)$}

The environment informativity rate $\left(F_{\text {Env.I }}\right)$ shows the depth of monitoring with regard to the environmental elements during the environmental evaluation:

$$
F_{\text {Env.I }}=\frac{\sum_{j=1}^{m} n_{\mathrm{p} j}}{\sum_{k=1}^{m} n_{\mathrm{t} k}}
$$

where $F_{\text {Env.I }}$ is the environment informativity rate, $n_{\mathrm{p} j}$ is the practical number of environmental parameters in the case of environmental element $j, n_{\mathrm{t} k}$ is the theoretical number of environmental parameters in the case of environmental element $k$, (Table 3 ), and $m$ is the number of environmental elements.

The environment informativity rate $\left(F_{\text {Env.I }}\right)$ indicates the coverage of the environmental parameters used in the investigation compared to the specified environmental parameters. The environmental impact assessment is more informative if the scope of the environmental parameters is larger.

$$
\lim _{n_{\mathrm{p} j} \rightarrow n_{\mathrm{t} k}}\left(F_{\text {Env.I }}\right)=1
$$

According to Eq. 11, the value of $F_{\text {Env.I }}$ approaches 1 if the practical number of environmental parameters $\left(n_{\mathrm{p} j}\right)$ closely resembles the theoretical number of parameters $\left(n_{\mathrm{t} k}\right)$.

\section{Informative Environment Qualifying Index ( $\left.I_{\mathrm{IEQ}}\right)$}

The final outcome of the method that is elaborated on is the informative environment qualifying index, which is a complex indicator (Eq. 12). The status of the environment is determined on the basis of the load of the different environmental elements and the informativity. Its value depends on the actual load of the environmental elements as well as the practical and theoretical numbers of environmental parameters.

From the reference radius of Table 4 during the evaluation, $I_{\mathrm{IEQ}}$ determines the accurate radius of the area derived from the actual load of the environmental elements:

$$
I_{\mathrm{IEQ}}=\sqrt{\frac{T_{\mathrm{L}}}{\pi F_{\mathrm{Env} . \mathrm{I}}}}
$$

where $I_{\mathrm{IEQ}}$ is the informative environment qualifying index, $T_{\mathrm{L}}$ is the total environmental load (Eq. 8), and $F_{\text {Env.I }}$ is the environment informativity rate (Eq. 10).

The application of the informative environment qualifying index provides a solid basis to compare the outcomes of different environmental evaluations since certain cases can differ from each other regarding the parameter sets. $I_{\mathrm{IEQ}}$ includes all these variables. The method can be expediently used to evaluate the environment before and after a disaster (e.g. the red mud disaster of Devecser), and the outcomes of the studies can be evaluated as a function of time. The method provides an opportunity to compare different cases (industrial parks, settlements, the natural environment) as well as provides a systemized and comprehensive approach to the evaluation.

\subsection{A case study}

Zirc is a small city in the heart of the Bakony Mountains in western Hungary. The city and its surroundings is a distinguished touristic area in Hungary with several natural attractions. An arboretum and National Parks are situated in the direct vicinity of the city. The water quality of the Cuha Stream which flows through the city is influenced 
Table 5: The measured parameters of Zirc on June 13, 2016

\begin{tabular}{ccc}
\hline \multicolumn{3}{c}{ The basic data of surface water } \\
Environmental parameters & Measured Value & Limit value \\
\hline Electrical conductivity $(\mu \mathrm{S} / \mathrm{cm})$ & 985 & 1,000 \\
$\mathrm{COD}_{\mathrm{cr}}(\mu \mathrm{g} / \mathrm{l})$ & 3,300 & 30,000 \\
$\mathrm{NO}_{3}-\mathrm{N}(\mu \mathrm{g} / \mathrm{l})$ & $1,497.24$ & 2,000 \\
$\mathrm{NH}_{4}-\mathrm{N}(\mu \mathrm{g} / \mathrm{l})$ & 50 & 400 \\
$\mathrm{PO}_{4}-\mathrm{P}(\mu \mathrm{g} / \mathrm{l})$ & 169 & 200 \\
\hline \multicolumn{2}{c}{ The basic data of air } & \\
Environmental parameters & Measured Value & Limit value \\
\hline $\mathrm{NO}^{3}\left(\mu \mathrm{g} / \mathrm{m}^{3}\right)$ & 3.708 & 100 \\
$\mathrm{NO}_{\mathrm{X}}\left(\mu \mathrm{g} / \mathrm{m}^{3}\right)$ & 8.406 & 200 \\
$\mathrm{CO}\left(\mu \mathrm{g} / \mathrm{m}^{3}\right)$ & 278.77 & 10,000 \\
$\mathrm{O}_{3}\left(\mu \mathrm{g} / \mathrm{m}^{3}\right)$ & 80.77 & 120 \\
$\mathrm{Benzene}\left(\mu \mathrm{g} / \mathrm{m}^{3}\right)$ & 0.331 & 10 \\
$\mathrm{PM}_{10}\left(\mu \mathrm{g} / \mathrm{m}^{3}\right)$ & 16 & 50 \\
\hline
\end{tabular}

by the wastewater treatment plant located here. The population of Zirc is 7,106 and the main economic activity in the region is agriculture.

During the field studies in the summer of 2016, two environmental elements were measured, namely surface water and air. The location of the measurement points is shown in Fig. 6.

In the case of surface water and air, the environmental parameters as defined in Table 5 were measured. The weights as well as quality indices, quality factors and quality indicators of parameters were determined and are summarized in Tables 6 and 7. FPi in the last rows of Tables 6 and 7 are used as a control since their total value must be equal to 360 . Values of $E_{\mathrm{L} j}$, as defined in Table 2 , constitute the basis of the numerical evaluation.

The value of the parameter quality index for the environmental parameter $\mathrm{PO}_{4}-\mathrm{P}$ calculated on the basis of Eq. 1 is illustrated below. The measured value of the parameter $\mathrm{PO}_{4}-\mathrm{P}$ was $169 \mathrm{mg} / \mathrm{l}$ and the limit value pertained to it was $200 \mathrm{mg} / \mathrm{l}[30]$.

$$
I_{\mathrm{P}_{\mathrm{PO}_{4}-\mathrm{P}}}=\frac{169\left(\frac{\mathrm{mg}}{\mathrm{l}}\right)}{200\left(\frac{\mathrm{mg}}{\mathrm{l}}\right)} 100=84.5
$$

The parameter quality factor for the environmental parameter $\mathrm{PO}_{4}-\mathrm{P}$ is determined on the basis of Eq. 2. The weight of $\mathrm{PO}_{4}-\mathrm{P}$ is 0.12 and the five numbers in the denominator include the weight of the five environmental parameters of water.

$$
F_{\mathrm{P}_{\mathrm{PO}_{4}-\mathrm{P}}}=\frac{0.12 \cdot 360}{0.06+0.01+0.06+0.12+0.12}=116.22
$$

The values of $I_{\mathrm{P} i}$ and $F_{\mathrm{P} i}$ calculated for the environmental parameters listed in Tables 6 and 7 constitute the basis of the calculation. Parts A and B of Fig. 7 refer to the surface water and air, respectively.

On the basis of the parametric analysis of surface water, it can be concluded that the maximum limit value is defined for $\mathrm{PO}_{4}-\mathrm{P}$. Therefore, in the following steps, the maximum weight $\left(\mathrm{F}_{\mathrm{Pi}}=\max \right)$ is assigned to $\mathrm{PO}_{4}-\mathrm{P}$. The electrical conductivity is close to the limit value and the parameter quality index of $\mathrm{NO}_{3}-\mathrm{N}$ is $\sim 75 \%$. These parameters are key to improve the water quality in Zirc and are represented by circles in Fig. 7. A similar analysis of air was also carried out.

For the environmental parameter $\mathrm{PO}_{4}-\mathrm{P}$, the parameter quality indicator is based on Eq. 2 using the parameter quality index (84.50) and parameter quality factor (116.22):

$$
\Delta_{P_{\mathrm{PO}_{4}-P}}=84.5^{2} \cdot 3.14 \cdot \frac{116.22}{360}=7,241.59
$$

The quantitative analysis of the environmental elements of surface water and air is depicted in Fig. 8. Parts A and B of Fig. 8 refer to the surface water and air, respectively.

The weights of the environmental parameters can be seen in Fig. 8 during the evaluation procedure (the total of the interior angles of the segments is equal to $F_{\mathrm{P} i}$ ). The radii of the sectors are identical to the values of $I_{\mathrm{P} i}$ which provide information on the quality. The load of the environmental element $\left(E_{\mathrm{LW}}\right)$ of the surface water is equal to 15,296 . The qualification system for evaluation of the different environmental elements (Table 2) functions by substitution. An assignment in the category of $R=50$ (environmental element with minimal disturbances, Table 2 is obtained. It can be concluded that the water quality of the Cuha Stream was disturbed to a minimal extent. Nevertheless, the ecosystem can tolerate this level of pollution.

By applying Eq. 4, the values of the environmental quality index express the actual loads of the environmental elements. On the basis of measurements in Zirc, the five parameters for surface water represent an area, $I_{\mathrm{EW}}$, equal to $R=69.78$, while the six environmental parameters for air represent an area, $I_{\mathrm{EA}}$, of $R=31.58$ :

$$
\begin{aligned}
& I_{\mathrm{EW}}=\sqrt{\frac{15,295.6}{3.14}}=69.78 \\
& I_{\mathrm{EA}}=\sqrt{\frac{3,132.57}{3.14}}=31.58
\end{aligned}
$$

Following these steps, the aforementioned algorithm was followed. The element quality factors for water and air, $F_{\mathrm{EW}}$ and $F_{\mathrm{EA}}$, were calculated according to the theoretical number of environmental parameters, altogether 92 parameters are to be monitored according to the specifications of GD 2010 [30] and GD 2011 [32]. In the case studies for surface water and air, five and six environmental parameters were investigated, respectively.

$$
\begin{aligned}
& F_{\mathrm{EW}}=\frac{5 \cdot 360}{92}=19.57 \\
& F_{\mathrm{EA}}=\frac{6 \cdot 360}{92}=23.48
\end{aligned}
$$

Next, the environmental element informativity rate was determined. The environmental element informativity rates for surface water and air are 0.08 and 


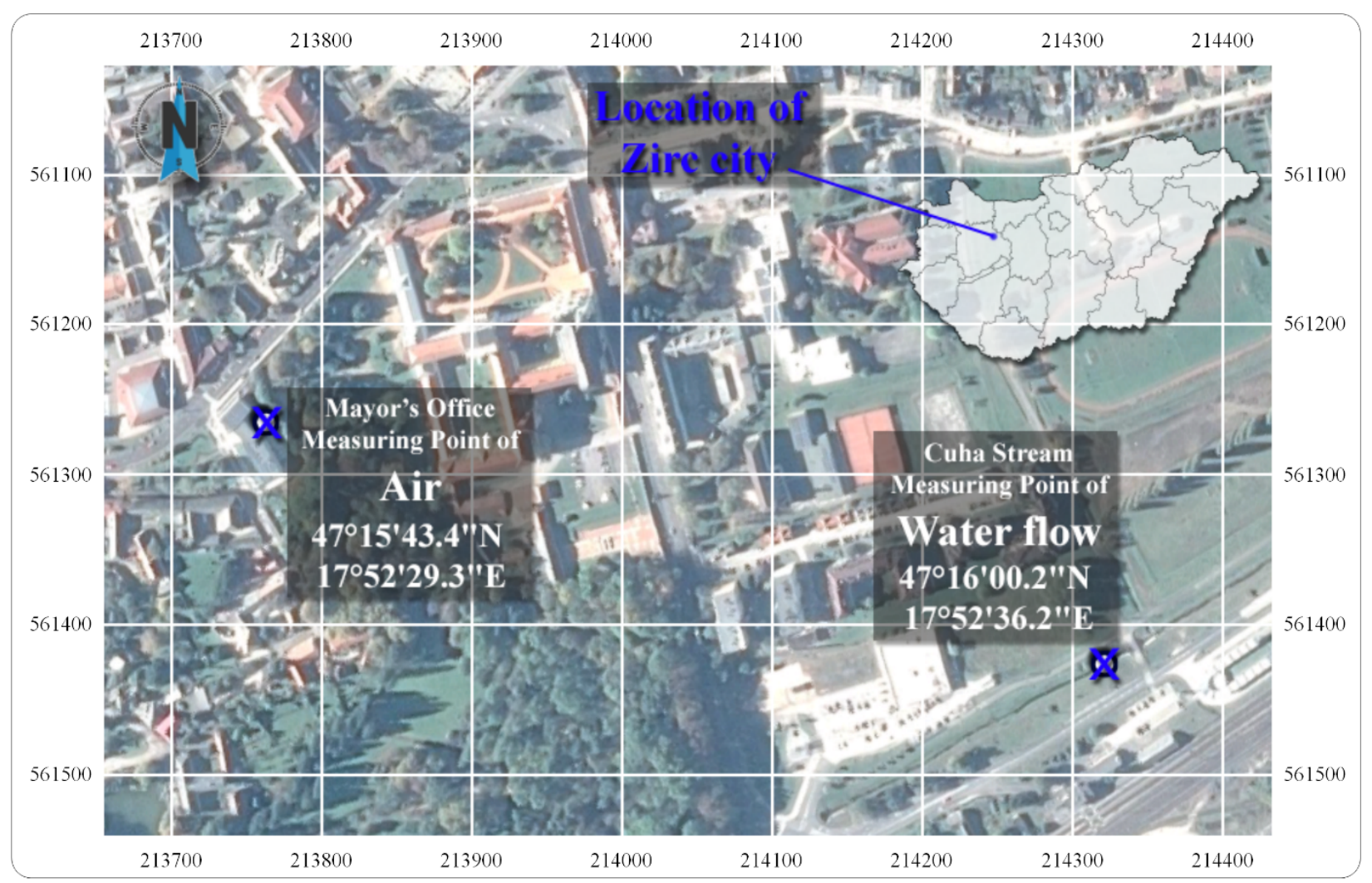

Figure 6: The measuring points and location of Zirc in Hungary

Table 6: The results of the calculations (Eqs. 1-3) for all measured parameters in the case of surface water from Cuha Stream, Zirc

\begin{tabular}{lcccccc}
\hline Parameter (unit) & Measured value & Limit value & $W_{i}$ & $I_{\mathrm{P} i}$ & $F_{\mathrm{P} i}$ & $\Delta_{\mathrm{P} i}$ \\
\hline Electrical conductivity $(\mu \mathrm{S} / \mathrm{cm})$ & 985 & 1,000 & 0.06 & 98.5 & 59.03 & $4,998.33$ \\
$\mathrm{COD}(\mathrm{mg} / \mathrm{l})$ & 3,300 & 30,000 & 0.01 & 11 & 9.5 & 10.03 \\
$\mathrm{NO}_{3}-\mathrm{N}(\mathrm{mg} / \mathrm{l})$ & $1,497.24$ & 2,000 & 0.06 & 74.86 & 59.03 & $2,887.19$ \\
$\mathrm{NH}_{4}-\mathrm{N}(\mathrm{mg} / \mathrm{l})$ & 50 & 400 & 0.12 & 12.5 & 116.22 & 158.47 \\
$\mathrm{PO}_{4}-\mathrm{P}(\mathrm{mg} / \mathrm{l})$ & 169 & 200 & 0.12 & 84.5 & 116.22 & $7,241.59$ \\
Total & $*$ n/a & $*$ n/a & $*$ n/a & $*_{\mathrm{n}} / \mathrm{a}$ & 360 & $E_{\mathbf{L W}}=15,296.6$ \\
\hline
\end{tabular}

*n/a: not applicable

Table 7: The results of the calculations (Eqs. 1-3) for all measured environmental parameters in the case of air in the vicinity of the Mayor's Office, Zirc

\begin{tabular}{ccccccc}
\hline Parameter (unit) & Measured value & Limit value & $W_{i}$ & $I_{\mathrm{P} i}$ & $F_{\mathrm{P} i}$ & $\Delta_{\mathrm{P} i}$ \\
\hline $\mathrm{NO}_{2}\left(\mu \mathrm{g} / \mathrm{Nm}^{3}\right)$ & 3.71 & 100 & 0.09 & 3.71 & 58.45 & 7.01 \\
$\mathrm{NO}_{\mathrm{X}}\left(\mu \mathrm{g} / \mathrm{Nm}^{3}\right)$ & 8.41 & 200 & 0.09 & 4.2 & 58.45 & 9.01 \\
$\mathrm{CO}\left(\mu \mathrm{g} / \mathrm{Nm}^{3}\right)$ & 278.77 & 10,000 & 0.01 & 2.79 & 6.32 & 0.43 \\
$\mathrm{O}_{3}\left(\mu \mathrm{g} / \mathrm{Nm}^{3}\right)$ & 80.77 & 120 & 0.09 & 67.31 & 58.45 & $2,310.77$ \\
$\mathrm{Benzene}\left(\mu \mathrm{g} / \mathrm{Nm}^{3}\right)$ & 0.33 & 10 & 0.14 & 3.31 & 89.17 & 8.53 \\
$\mathrm{PM}_{10}\left(\mu \mathrm{g} / \mathrm{Nm}^{3}\right)$ & 16 & 50 & 0.14 & 32 & 89.17 & 796.83 \\
Total & $* \mathrm{n} / \mathrm{a}$ & $* \mathrm{n} / \mathrm{a}$ & $* \mathrm{n} / \mathrm{a}$ & $* \mathrm{n} / \mathrm{a}$ & 360 & $E_{\mathrm{LA}}=3,132.57$ \\
\hline
\end{tabular}

*n/a: not applicable 

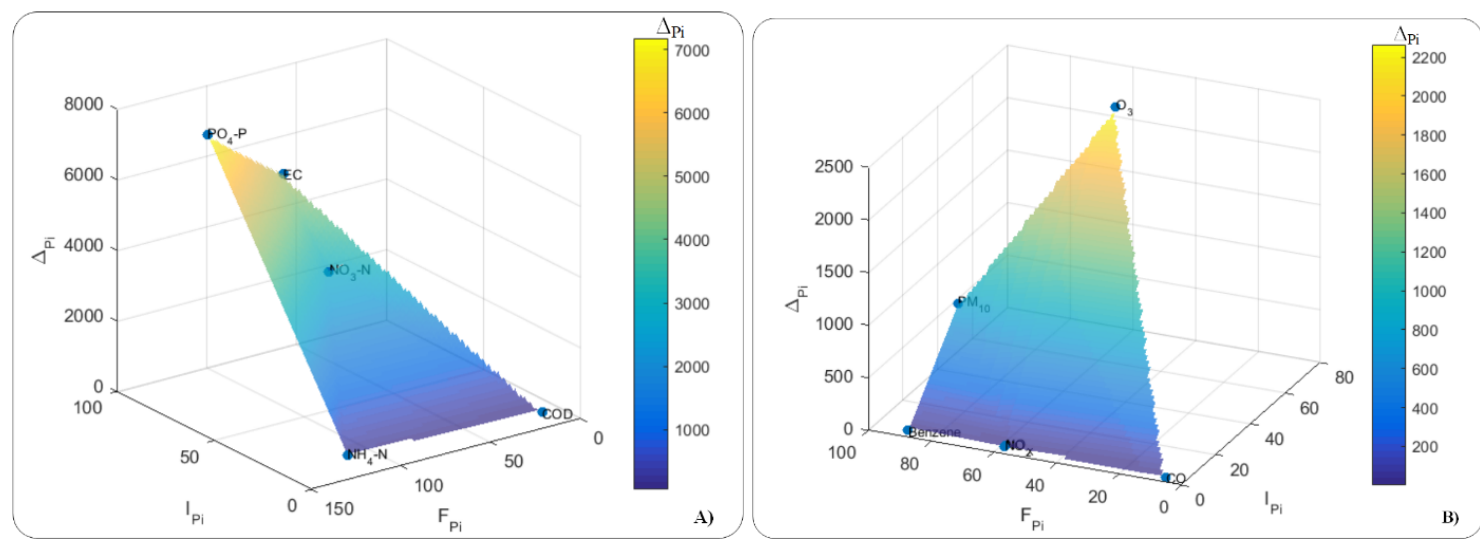

Figure 7: Immission analysis of the surface water (left-hand side, Part A) and air (right-hand side, Part B)
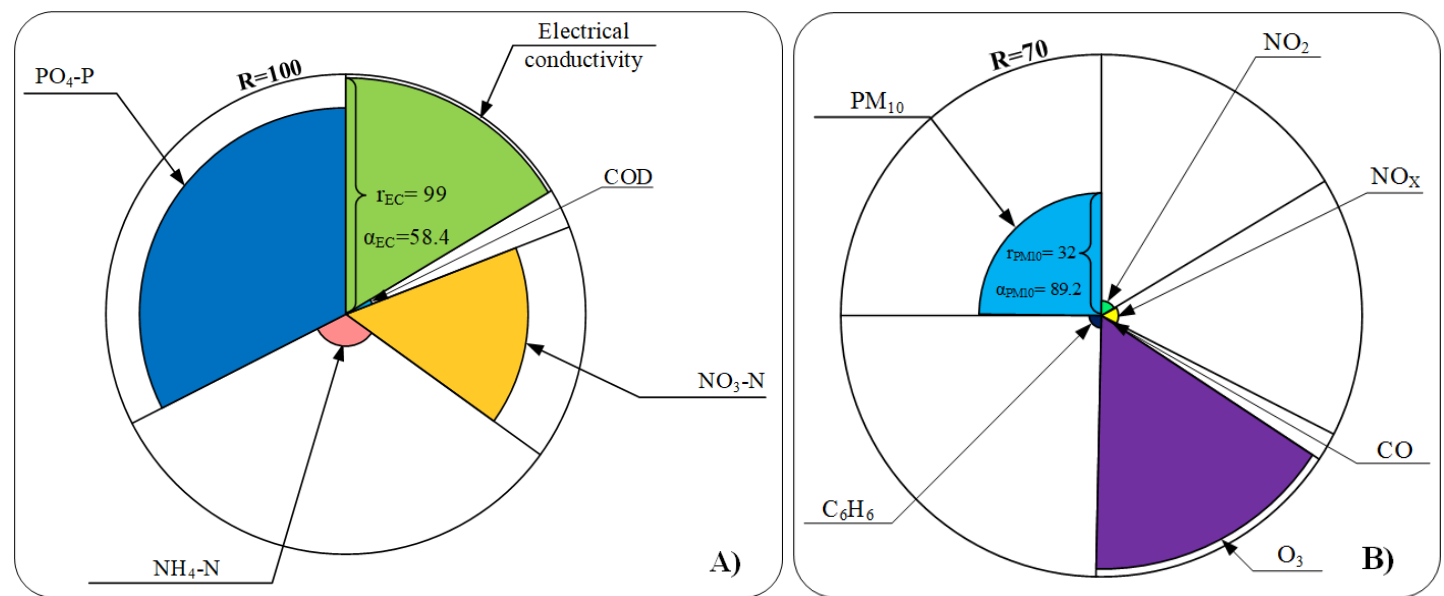

Figure 8: The quantitative analysis of the environmental elements (left-hand side: water, Part A; right-hand side: air, Part B)

0.18 , respectively. It should be noted that the total of $\left.F_{\mathrm{EQW}} / F_{\mathrm{EIW}}=19.57 / 0.08=230.87\right)$ and $\left.F_{\mathrm{EQA}} / F_{\mathrm{EIA}}=23.48 / 0.18=129.13\right)$ is equal to 360 .

$$
\begin{aligned}
& F_{\text {IW }}=\frac{5}{59}=0.08 \\
& F_{\text {IA }}=\frac{6}{33}=0.18
\end{aligned}
$$

On the basis of Eq. 7, the load of the whole environment $\left(\Delta_{\mathrm{E} j}\right)$ can be calculated using the actual load of the environmental elements. The actual load is substituted into the equation in the square/quadratic form, while $n_{\mathrm{p} j} / n_{\mathrm{t} j}$ for the informativity is linear.

$$
\begin{gathered}
\Delta_{\mathrm{EW}}=\frac{69.78^{2} \cdot 3.14 \cdot 19.57}{360}=831.28 \\
\Delta_{\mathrm{EA}}=\frac{31.58^{2} \cdot 3.14 \cdot 23.48}{360}=204.3
\end{gathered}
$$

The total load of the environment is equal to the total of the summarized loads of the environmental elements (Eq. $8)$. In the case of Zirc, the larger proportion of environmental load stems from the surface-water pollution and the load of the air pollution represents roughly $20 \%$.

$$
T_{\mathrm{L}}=831.28+204.3=1,035.58
$$

The whole environment can be evaluated by the dynamical reference areas as given by Eq. 9 and Table 4 .

By substituting $T_{\mathrm{L}}$ into Table 4 , it can be stated that the parameters describing the status of the environment are close to the concentrations of limit values. The radius assigned to the environmental quality of the city is equal to $R=50$.

$$
A_{50}=50^{2} \cdot 3.14 \cdot 0.12=939
$$

In the aforementioned formula, the radius is equal to 50 , representing the worst category of quality. The environmental element informativity rate is 0.12 (Eq. 10) which provides information on the number of environmental parameters in the study.

$$
F_{\text {Env.I }}=\frac{5+6}{59+33}=0.12
$$

The Informative Environment Qualifying Index $\left(I_{\mathrm{IEQ}}\right)$ is calculated on the basis of Eq. 12:

$$
I_{\mathrm{IEQ}}=\sqrt{\frac{1,035.58}{3.14 \cdot 0.12}}=52.51
$$

$I_{\text {IEQ }}$ of Zirc is 52.51 . By substituting this value into Table 4 , it can be seen that the environmental parameters 
describing the status of the environment closely resemble the natural conditions with minimal disturbances. Specialists agree with the results, which are supported by the outcome of the field study.

\section{Conclusion}

The novelty of the Informative Environment Qualifying Index method is that the maximum environmental loads of the environmental parameters as stipulated in the legal specifications and the actually measured/calculated levels of pollution are taken into consideration when compared to the methods published in the literature. During the evaluation, the algorithm is applied at different levels, namely at the levels of environmental parameters, environmental elements and the total environment, to expediently elaborate on the planning of environmental mitigation measures. The quantitative methods used in the environmental impact assessment procedure include several subjective components during the weighting/ranking/scaling which could result in different interpretations with regard to the outcome of the evaluation. The Informative Environment Qualifying Index method is based on the specifications of national regulations, while the weight of the environmental elements depends on their status and the number of environmental parameters included in the study.

The Informative Environment Qualifying Index method is suitable for following up and monitoring the status of the environment in the cases of protected areas, national parks, urban areas, disasters, etc. The applicability of the method was demonstrated in the case of Zirc, a small city in the heart of the Bakony Mountains in western Hungary.

The scope of the evaluation ranges from the category "environment close to the natural conditions or with minimal disturbances" to "natural environmental elements with indirect or direct anthropogenic impacts". The method casts light on the significant environmental impacts without concealing extreme situations nor distorting the final conclusions.

\section{Acknowledgement}

The financial support of Széchenyi 2020 under project GINOP-2.3.2-15-2016-00016 is acknowledged. The financial support of Széchenyi 2020 under the project EFOP-3.6.1-16-2016-00015 is acknowledged.

\section{Nomenclature}

$\Delta_{\mathrm{E} j} \quad$ Quality indicator for environmental element $j$

$\Delta_{\mathrm{P} i} \quad$ Quality indicator for environmental parameter $i$

A Subscript, air

$A_{\mathrm{D}} \quad$ Dynamical reference area (level of the total environment)

$A_{\mathrm{S}} \quad$ Reference area (level of the environmental elements)

$E_{\mathrm{L} j} \quad$ Environmental element load of environmental element $j$

$F_{\mathrm{E} j} \quad$ Quality factor for environmental element $j$

$F_{\text {Env.I }} \quad$ Informativity rate of total environment

$F_{\mathrm{I} j} \quad$ Informativity rate of environmental element $j$

$F_{\mathrm{P} i} \quad$ Quality factor for environmental element $i$

G Subscript, groundwater

$I_{\mathrm{E} j} \quad$ Quality index for environmental element $j$

$I_{\mathrm{IEQ}} \quad$ Informative environment qualifying index

$I_{\mathrm{P} i} \quad$ Quality index for environmental element $i$

L Subscript, surface water: lake

$L_{\mathrm{v} i} \quad$ Limit value of environmental parameter $i$

$m \quad$ Number of environmental elements

$M_{\mathrm{v} i} \quad$ Measured value of environmental parameter $i$

$n_{\mathrm{p} j} \quad$ Practical number of parameters in the case of element $j$

$n_{\mathrm{t} k} \quad$ Theoretical number of parameters in the case of element $k$

$R \quad$ Reference radius

S Subscript, soil

$T_{\mathrm{L}} \quad$ Total environmental load

W Subscript, surface water: water flow

$W_{i}, W_{l} \quad$ Weights of environmental parameters $i$ and $l$

\section{REFERENCES}

[1] Kılk1ş, Ş.: Composite index for benchmarking local energy systems of Mediterranean port cities, Energy, 2015, 92(3), 622-638 DOI: 10.1016/j.energy.2015.06.093

[2] Kılkış, Ş.: Sustainable development of energy, water and environment systems index for Southeast European cities, J. Cleaner Prod., 2016, 130(1), 222-234 DOI: 10.1016/j.jclepro.2015.07.121

[3] Sebestyén, V.; Somogyi V.; Utasi A.: Adapting the SDEWES index to two Hungarian cities, Hung. J. Ind. Chem., 2017, 45(1), 49-59 DOI: 10.1515/hjic-20170008

[4] Toro, J.; Requena, I.; Duarte, O.; Zamorano, M.: A qualitative method proposal to improve environmental impact assessment, Environ. Impact Assess. Rev., 2013, 43, 9-20 DOI: 10.1016/j.eiar.2013.04.004

[5] Pavlickova, K.; Vyskupova, M.: A method proposal for cumulative environmental impact assessment based on the landscape vulnerability evaluation, Environ. Impact Assess. Rev., 2015, 50, 74-84 DOI: 10.1016/j.eiar.2014.08.011 
[6] Herva, M.; Roca, E.: Review of combined approaches and multi-criteria analysis for corporate environmental evaluation, J. Cleaner Prod., 2013, 39, 355-371 DOI: 10.1016/j.jclepro.2012.07.058

[7] Carvalho, A.; Milmoso, A. F.; Mendes, A.N.; Matos, H. A.: From a literature review to a framework for environmental process impact assessment index, J. Cleaner Prod., 2014, 64, 36-62 DOI: 10.1016/j.jclepro.2013.08.010

[8] Caeiro, S.; Vaz-Fernandes, P.; Martinho, A. P.; Costa, P. M.; Silva, M. J.; Lavinha, J.; Matias-Dias, C.; Machado, A.; Castanheira, I.; Costa, M. H.: Environmental risk assessment in a contaminate estuary: An integrated weight of evidence approach as a decision support tool, Ocean Coastal Manage., 2017, 143, 51-62 DOI: 10.1016/j.ocecoaman.2016.09.026

[9] Phillips, J.: A quantitative-based evaluation of the environmental impact and sustainability of a proposed onshore wind farm in the United Kingdom, Renewable Sustainable Energy Rev., 2015, 49, 1261-1270 DOI: 10.1016/j.rser.2015.04.179

[10] Phillips, J.; Gholamalifard, M.: Quantitative evaluation of the sustainability or unsustainability of municipal solid waste options in Tabriz, Iran. Int. J. Environ. Sci. Technol., 2016, 13(6), 1615-1624 DOI: 10.1007/s13762-016-0997-0

[11] Robu, B. M.; Jitar, O.; Teodosiu, C,; Strungaru, S. A.; Nicoara, M.; Plavan, G.: Environmental impact and risk assessment of the main pollution sources from the romanian black sea coast, Environ. Eng. Manage. J., 2015, 14(2), 331-340, http://eemj. eu/index.php/EEMJ/article/view/2184

[12] Sun, R.; Wang, Z,: A comprehensive environmental impact assessment method for shale gas development, Nat. Gas Ind. B, 2015, 2(2-3), 203-210 DOI: 10.1016/j.ngib.2015.07.012

[13] Robu, B. M.; Bulgariu, D.; Bulgariu, L.; Macoveanu, M.: Quantification of impact and risk induced in surface water by heavy metals: case study Bahlui River Iasi, Environ. Eng. Manage. J., 2008, 7(3), 263-267 http://eemj.eu/index.php/EEMJ/ article/view/417

[14] Robu, B. M.; Căliman, F. A.; Beţianu, C.; Gavrilescu, M.: Methods and procedures for environmental risk assessment, Environ. Eng. Manage. J., 2007, 6(6), 573-592 http://eemj.eu/index. php/EEMJ/article/view/371

[15] Dee, N.; Baker, J.; Drobny, N.; Duke, K.; Whitman, I.; Fahringer, D.: An environmental evaluation system for water resource planning, Water Resour. Res., 1972, 9(3), 523-536 DOI: 10.1029/WR009i003p00523

[16] Ferreira, A. P.; da Cunha, C. L. N.; Kling, A. S. M.: Environmental evaluation model for water resource planning. Study case: Piabanha hydrographic basin, Rio de Janeiro, Brazil, Revista Elektoronicado Promeda., 2008, 2(1), 7-18
[17] Foden, J.; Rogers, S. I.; Jones, A. P.: A critical review of approaches to aquatic environmental assessment, Mar. Pollut. Bull., 2008, 56(11), 1825-1833 DOI: 10.1016/j.marpolbul.2008.08.017

[18] Yu, C.; Yin, X.; Li, Z.; Yang, Z.: A universal calibrated model for the evaluation of surface water and groundwater quality: Model development and a case study in China, J. Environ. Manage., 2015, 163, 20 27 DOI: 10.1016/j.jenvman.2015.07.011

[19] Wu, J.; Pu, G.; Ma, Q.; Qi, H.; Wang, R.: Quantitative environmental risk assessment for the iron and steel industrial symbiosis network, J. Cleaner Prod., 2017, 157, 106-117 DOI: 10.1016/j.jclepro.2017.04.094

[20] Han, R.; Zhou, B.; An, L.; Jin, H.; Ma, L.; Li, N.; $\mathrm{Xu}, \mathrm{M}$.; Li, L.: Quantitative assessment of enterprise environmental risk mitigation in the context of Na-tech disasters, Environ. Monit. Assess., 2019, 191(4), 1-13 DOI: 10.1007/s10661-019-7351-1

[21] Meex, E.; Hollberg, A.; Knapen, E.; Hildebrand, L.; Verbeeck, G.: Requirements for applying LCAbased environmental impact assessment tools in the early stages of building design, Build. Environ., 2018, 133, 228-236 DOI: 10.1016/j.buildenv.2018.02.016

[22] Rocha, C. A.; Sousa, F. W.; Zanella, M. E.; Oliveira, A. G.; Nascimento, R. F.; Souza, O. V.; Cajazeiras, I. M. P.; Lima, J. L. R.; Cavalcante, R. M.: Environmental quality assessment in areas used for physical activity and recreation in a city affected by intense urban expansion (Fortaleza-CE, Brazil): Implications for public health policy, Environ. Sci. Pollut. Res., 2017, 9(3), 169-182 DOI: 10.1007/s12403-0160230-x

[23] Németh, J.; Sebestyén, V.; Juzsakova, T.; Domokos, E.; Dióssy, L.; Le Phuoc, C.; Huszka, P.; Rédey, Á.: Methodology development on aquatic environmental assessment. Environ. Sci. Pollut. Res., 2017, 24(12), 11126-11140 DOI: 10.1007/s11356-016-7941-1

[24] Sebestyén, V.; Németh, J.; Juzsakova, T.; Domokos, E.; Kovács, Zs.; Rédey, Á.: Aquatic environmental assessment of Lake Balaton in the light of physicalchemical water parameters, Environ. Sci. Pollut. Res., 2017, 24(32), 25355-25371 DOI: 10.1007/s11356017-0163-3

[25] Sebestyén, V.; Németh, J.; Juzsakova, T.; Domokos, E.; Rédey, Á.; Lake Balaton: Water Quality of the Largest Shallow Lake in Central Europe, Encyclopedia of Water: Science, Technology, and Society, 2019, 1-15 DOI: 10.1002/9781119300762.wsts0063

[26] Jiang, L.; Zhou, H.; Bai, L.; Zhou, P.: Does foreign direct investment drive environmental degradation in China? An empirical study based on air quality index from a spatial perspective, J. Cleaner Prod., 2018, 176, 864-872 DOI: 10.1016/j.jclepro.2017.12.048

[27] Wang, D.; Wei, S.; Luo, H.; Yue, C.; Grunder, O.: A novel hybrid model for air quality index forecasting based on two-phase decomposition technique and modified extreme learning ma- 
chine, Sci. Total Environ., 2017, 580, 719-733 DOI: 10.1016/j.scitotenv.2016.12.018

[28] Zuhaib, S.; Manton, R.; Griffin, C.; Hajdukiewicz, M.; Keana, M. M.; Goggins, J.: An Indoor Environmental Quality (IEQ) assessment of a partiallyretrofitted university building, Build. Environ., 2018, 139, 69-85 DOI: 10.1016/j.buildenv.2018.05.001

[29] Sanz-Garcia, M. T.; Caselles Moncho, A.; Micó Ruiz, J. C.; Soler Fernández, D.: Including an environmental quality index in a demographic model, Int. J. Global Warming 2016, 9(3), 362-396 DOI: 10.1504/IJGW.2016.075448

[30] Sebestyén, V.; Somogyi, V.; Szőke, Sz.; Utasi, A.: Adapting the SDEWES index to two Hungarian cities, Hung. J. Ind. Chem., 2017, 45(1), 49-59 DOI: 10.1515/hjic-2017-0008
[31] GD (2010) Government Decree No. 10/2010. (VIII. 18.) of Ministry of Rural Development (VM) defining the rules for establishment and use of water pollution limits of surface water (in Hungarian)

[32] GD (2006) Joint Government Decree No. 6/2009. (IV. 14.) of Ministry of Health and Ministry of Agriculture and Rural Development (KvVM-EüMFVM) from the limit values and the measurement of pollutants for the protection from pollution of soil and groundwater (in Hungarian)

[33] GD (2011) Government Decree No. 4/2011. (I. 14.) of Ministry of Rural Development (VM) from the ambient air quality limit values and the emission limit values of stationary point sources of air pollutants (in Hungarian) 